\title{
Comprehensive co-expression analysis reveals TMC8 as a prognostic immune-associated gene in head and neck squamous cancer
}

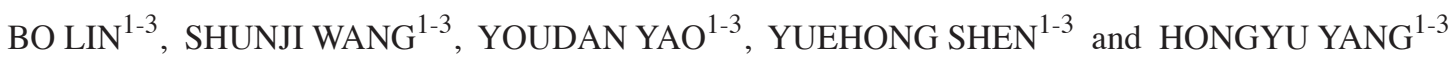 \\ ${ }^{1}$ Department of Oral and Maxillofacial Surgery, Stomatological Center, Peking University Shenzhen Hospital; \\ ${ }^{2}$ Department of Oral and Maxillofacial Surgery, Guangdong Provincial High-Level Clinical Key Specialty; \\ ${ }^{3}$ Department of Oral and Maxillofacial Surgery, Guangdong Province Engineering Research Center \\ of Oral Disease Diagnosis and Treatment, Shenzhen, Guangdong 518036, P.R. China
}

Received October 21, 2020; Accepted February 17, 2021

DOI: $10.3892 / \mathrm{ol} .2021 .12759$

\begin{abstract}
The occurrence and prognosis of head and neck squamous cell cancer (HNSC) is closely associated with human papillomavirus (HPV) infection. Transmembrane channel-like 8 (TMC8) is a key gene affecting the susceptibility of HPV and that plays an important role in $\mathrm{T}$ cell regulation. However, the mechanism by which TMC8 affects T cells and whether it further affects the prognosis of patients with HNSC remains unclear. In the present study, oral cancer cell lines and independent tumor specimens were used to detect TMC8 expression in HNSC. Differential expression of TMC8, methylation status, function and associated signaling pathways were further analyzed. Then, multiple databases were cross-analyzed for the relationship of TMC8 with immune cell infiltration and its impact on the prognosis of numerous types of cancer. The results showed that TMC8 was upregulated in HNSC and high expression was predictive of an improved prognosis. Furthermore, TMC8 was concentrated in multiple immune-associated signaling pathways and the expression of TMC8 was associated with the infiltration of $\mathrm{CD}^{+} \mathrm{T}$ cells and their subsets, including $\mathrm{CD}^{+} \mathrm{T}$ cells, B cells and macrophages, suggesting that TMC8 may play an anti-HPV role by regulating $\mathrm{CD}^{+} \mathrm{T}$ cells. Thus, TMC8 plays an anti-HPV role by regulating the infiltration level of $\mathrm{CD} 4^{+} \mathrm{T}$ cells, and could therefore be used as a potential prognostic marker for patients with HNSC.
\end{abstract}

Correspondence to: Dr Hongyu Yang or Dr Yuehong Shen, Department of Oral and Maxillofacial Surgery, Stomatological Center, Peking University Shenzhen Hospital, 1120 Lianhua Road, Futian, Shenzhen, Guangdong 518036, P.R. China

E-mail: yanghongyu0520@163.com

E-mail: yuehongshen@hotmail.com

Key words: transmembrane channel-like 8, immune, head and neck squamous cancer, expression, prognosis

\section{Introduction}

Head and neck squamous cell carcinoma (HNSC) is the sixth most common malignancy in the world (1), which predominantly develops from squamous cell epithelia according to Chaturvedi et al in 2013 (2). The main risk-factors of HNSC are cigarette smoking, excessive alcohol use and the presence of human papillomavirus (HPV). Although the overall survival (OS) time and quality of life have been enhanced by improved standard treatment and supportive care (3), HNSC prognosis remains poor with a 5-year OS rate of $\sim 50 \%$ worldwide by 2011 (4).

In recent years, some biomarkers have been identified and used in the diagnosis of HNSC (5). For example, matrix metalloproteinases (MMPs), which promote tumor invasion and metastasis, have been found to be significantly increased in the serum of patients with head and neck cancer and are promising biomarkers for the diagnosis of HNSC (6). In addition, DNA methylation is a major epigenetic change that often precedes the malignant proliferation of cells. The identification of DNA methylation changes is of great significance for the early detection of tumors (7). At present, the methylation status of genes such as p16, cyclin-dependent kinase and stratifin have been associated with HNSC $(8,9)$. However, the sensitivity and specificity of these biomarkers reported in literatures are quite different.

Since immune-associated mechanisms have a critical role in HNSC, immunotherapies represent a promising strategy for treatment $(10,11)$. Immune checkpoints can respond to pathogens by regulating the balance of immune stimuli and inhibitory signals, or as regulators of mutant/overexpressing $\mathrm{T}$ cell immune responses $(12,13)$. Previous research has demonstrated that the interaction between programmed cell death protein-1 (PD-1) and PD ligand-1 is a critical immune checkpoint. Inhibiting PD-1 has been found to exhibit high treatment efficacy for melanoma and is now approved for the treatment of HNSC (14,15). However, current anti-PD-1 immunotherapies do not generate good responses from patients with advanced HNSC. According to reports, the median OS time was 7.5 months, and some patients show resistance $(16,17)$. Additionally, 
several studies have reported that patients with a greater number of tumor-infiltrating lymphocytes display increased survival in HPV-positive and -negative oropharyngeal disease (18-21). Therefore, there is a need to elucidate the specific immune phenotypes of tumor-immune relationships and identify novel immunological targets for the treatment of HNSC.

As a protein-coding gene, transmembrane channel-like 8 (TMC8) is not yet fully understood. TMC6 and TMC8 null mutations have been shown to result in severe susceptibility to cutaneous ( $\beta$-type) HPV infections, causing a rare syndrome termed epidermodysplasia verrucciformis (EV) $(22,23)$. Moreover, an association between TMC8 variants and susceptibility to skin and cervical cancer has been observed $(23,24)$. Notably, patients with HNSC are often accompanied by HPV infection, but the expression level of TMC8 and its relationship with patient prognosis and clinical stage has not yet been reported. Previous studies have shown that $\mathrm{T}$ lymphocytes exhibit high levels of TMC8 gene expression, indicating that TMC8 plays a multifunctional role in the mechanisms associated with tumor infiltration $(25,26)$. However, the impact of this gene on the OS time of patients with HNSC and the underlying function of TMC8 in tumor-immune interactions remains unclear.

Oral squamous cell cancer is a typical representative of HNSC, accounting for the majority of $\operatorname{HNSC}(1,4)$. As shown in the workflow of Fig. 1, the expression of TMC8 was examined in oral cancer cell lines, clinical specimens and The Cancer Genome Atlas (TCGA) database and its relationship with the OS time of patients with HNSC was also evaluated. Moreover, its function and role in the immune cell network, as well as its impact on prognosis in multiple cancers (pan-cancers) were analyzed. The purpose of the present study was to explore the role of TMC8 in the immune microenvironment and to further clarify its impact on the incidence and outcome of HNSC.

\section{Materials and methods}

Acquisition of clinical specimens. Oral squamous cell carcinoma (OSCC) and adjacent normal tissues were collected from patients with HNSC at the Peking University Shenzhen Hospital (Shenzhen, China) between January 2017 and December 2019. HNSC was diagnosed and classified by two independent pathologists based on the World Health Organization classification system (27). The specimens were all taken from the tongue cancer resection process, and the distance between tumor tissue and adjacent normal tissue was greater than $2 \mathrm{~cm}$. Specimens from patients with a history of preoperative chemotherapy were excluded. The study was approved by The Ethics Committee of Peking University Health Science Center (Guangdong, China). Informed consent was obtained from patients before the study began.

Immunochemical staining. The above mentioned, obtained from the operating room without pre-embedded OSCC samples were fixed in $10 \%$ neutral buffered formalin for $24 \mathrm{~h}$ at room temperature, dehydrated in gradient alcohol solution $(50,70,80$, 95, 95 and 100 alcohol, each for $1 \mathrm{~h}$ ) and paraffin-embedded. Paraffin-embedded tumor sections with a thickness of $5-\mu \mathrm{m}$ were deparaffinized with xylene I for $15 \mathrm{~min}$, xylene II for 10 min, and rehydrated with $100 \%$ ethanol and 100, 95, 95 and
$80 \%$ ethanol for $5 \mathrm{~min}$ each. Sections were then washed twice for 5 min each with $\mathrm{dH} 2 \mathrm{O}$. Slides were heated in a microwave in 1X citrate antigen retrieval Solution (cat. no. MVS-0066; MBX Bioscience) until boiling, followed by incubation at the boiling state for $20 \mathrm{~min}$. After cooling, sections were washed in PBS three times for $5 \mathrm{~min}$ each. Antigen retrieval was achieved by blocking with $3 \% \mathrm{H}_{2} \mathrm{O}_{2}$ for $30 \mathrm{~min}$ at room temperature. The aforementioned washing steps were repeated and then blocking was performed using goat serum (cat. no. ZLI-9022; OriGene Technologies, Inc.) at room temperature for $20 \mathrm{~min}$. Then the sections were incubated with antibodies against TMC8 (cat. no. ab69859; 1:75; Abcam) overnight at $4^{\circ} \mathrm{C}$. The slides were then incubated with a biotin-labeled secondary antibody UltraSensitive ${ }^{\mathrm{TM}}$ SP (Mouse/Rabbit) IHC kit (cat. no. KIT-9710; MBX Biotechnologies, Inc.) to TMC8 for $30 \mathrm{~min}$ at room temperature. The aforementioned washing steps were repeated and the slices were stained with DAB (cat. no. DAB-0031; MBX Biotechnologies, Inc.) at room temperature for $\sim 1 \mathrm{~min}$. All images shown are wide-field light microscopy images acquired at sufficient resolution.

Cell culture. Human oral squamous cell carcinoma cell lines SCC9, SCC15, SCC25 and CAL27 were obtained from the American Type Culture Collection. Human oral keratinocyte (HOK) cells were obtained from The Cell Bank of Type Culture Collection of The Chinese Academy of Sciences. SCC15, SCC25, CAL27 and HOK cells were maintained in DMEM supplemented with $10 \%$ FBS and $1 \%$ penicillin and streptomycin sulfate (all Gibco; Thermo Fisher Scientific, Inc.). SCC9 cells were cultured in 1:1 DMEM/F12 (Gibco; Thermo Fisher Scientific, Inc.) containing $10 \% \mathrm{FBS}, 1 \%$ penicillin and streptomycin sulfate, $1 \%$ sodium pyruvate (Gibco; Thermo Fisher Scientific, Inc.) and $400 \mathrm{ng} / \mathrm{ml}$ hydrocortisone (MedChemExpress). All cells were cultured at $37^{\circ} \mathrm{C}$ and $5 \% \mathrm{CO}_{2}$.

$R N A$ extraction and reverse transcription quantitative $P C R$ $(R T-q P C R)$. Total RNA from frozen tissues or cultured cells was extracted using TRIzol ${ }^{\circledR}$ reagent (Invitrogen; Thermo Fisher Scientific, Inc.), according to the manufacturer's protocol. A PrimeScript $^{\mathrm{TM}}$ RT reagent kit with gDNA Eraser (Perfect Real Time) (cat. no. RR047A; Takara Bio, Inc.) was used for reversetranscribing the RNA into cDNA, as per the manufacturer's instructions. RT-qPCR was performed with TB Green ${ }^{\circledR}$ Premix Ex Taq ${ }^{\mathrm{TM}}$ II (Tli RNaseH Plus) (cat. no. RR820A; Takara Bio, Inc.) and was monitored using an ABI PRISM ${ }^{\mathrm{TM}} 7500$ Sequence Detection system (Applied Biosystems; Thermo Fisher Scientific, Inc.). Thermocycling conditions were as follows: Initial denaturation at $95^{\circ} \mathrm{C}$ for $5 \mathrm{~min}$, followed by followed by denaturation at $95^{\circ} \mathrm{C}$ for $5 \mathrm{sec}$; annealing at $58^{\circ} \mathrm{C}$ for $30 \mathrm{sec}$ and elongation at $72^{\circ} \mathrm{C}$ for $20 \mathrm{sec}$, for 40 cycles. The following primers were used for qPCR: $\beta$-Actin, forward: 5'-AAACTGG AACGGTGAAGGTG-3' and reverse: 5'-AGTGGGGTGGCT TTTAGGAT-3'; TMC8, forward: 5'-GAACTACCCTCCCAA CACG-3' and reverse: 5'-TGCTCTTGTCTCTGCCAATG-3'. Comparative quantification was performed with either the $\Delta \mathrm{Cq}$ or the $2^{-\Delta \Delta \mathrm{Cq}}$ method (28). RT-qPCR was used to determine the expression of TMC8 in SCC9, SCC15, SCC25 and CAL27 cell lines. Data from three independent experiments were obtained, the mean value \pm standard deviation was calcualted and unpaired Student's t-test was used. 


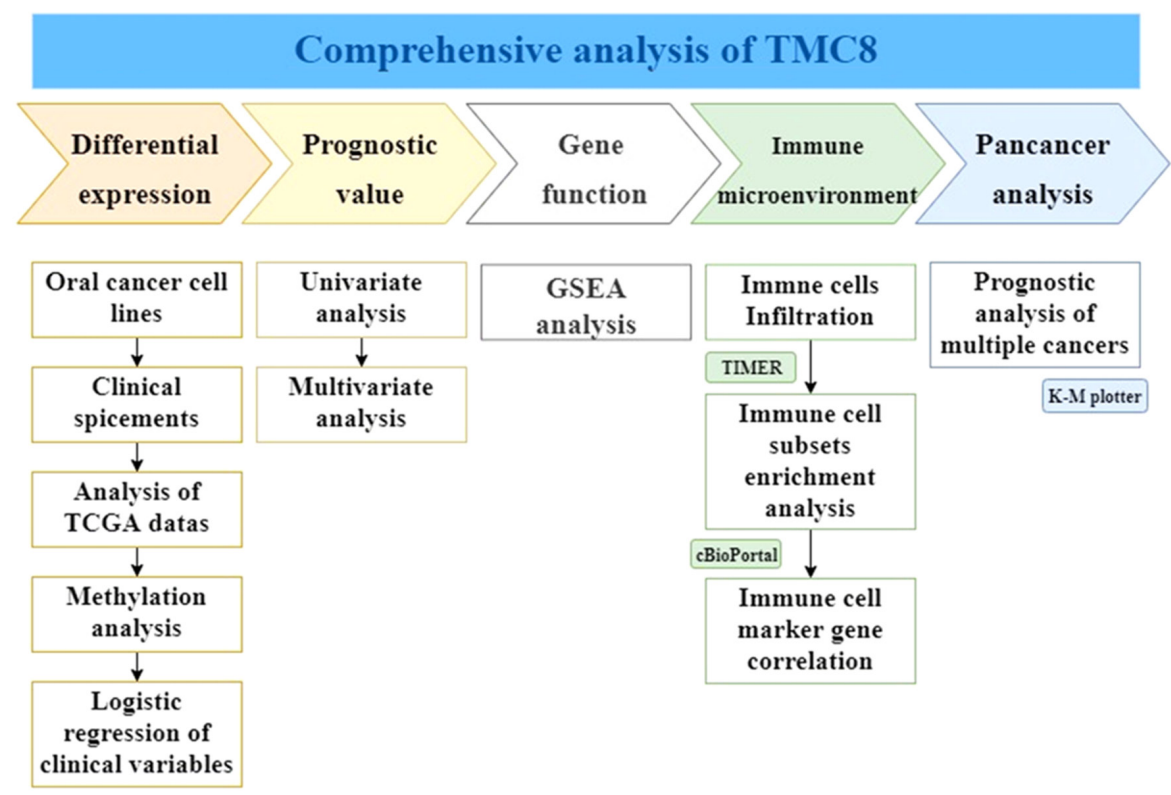

Figure 1. Workflow of the study. A comprehensive analysis of TMC8 was conducted. In the first line, from left to right, the five parts of differential expression, prognostic value of head and neck squamous cancer, gene function, immune infiltration relationship and prognostic effect on pan-cancers are analyzed and are marked with different colors. Below each part, the specific analysis content is listed. TMC8, transmembrane channel-like 8; GSEA, gene set enrichment analysis; TCGA, The Cancer Genome Atlas; K-M, Kaplan-Meier; TIMER, Tumor Immune Estimation Resource.

Acquisition of mRNA data. TMC8 gene expression and methylation data, as well as the corresponding clinical information, were downloaded from TCGA website (https://portal. gdc.cancer.gov) for HNSC and estimated as $\log 2(\mathrm{x}+1)$ transformed RNA sequencing by expectation-maximization normalized counts (29). A total of 528 patients with HNSC were sampled, containing 44 patients with adjacent non-tumorous tissue as the control group. All data were processed using R studio software version 3.5.3 (30). The 'ESTIMATE' R package was used to predict the presence of infiltrating stromal/immune cells in tumor tissues using gene expression data (31).

Gene Expression Profiling Interactive Analysis (GEPIA) and survival analysis. The online database GEPIA (http://gepia. cancer-pku.cn/index.html) was used to analyze the differential expression of the TMC8 and its prognostic value.

Methylation and gene expression analyses. DNA methylation data from TCGA contained $\beta$-values for $485,577 \mathrm{CpG}$ sites. The $\beta$-value was calculated as $(\mathrm{M} / \mathrm{M}+\mathrm{U})$ and ranged from zero to one, where $\mathrm{M}$ was the frequency of the methylated allele and $U$ was the frequency of the unmethylated allele. Therefore, higher $\beta$-values indicated higher levels of methylation. Levels of TMC8 methylation between HNSC and normal tissues were compared. In addition, the association between TMC8 expression and its DNA methylation status was investigated.

Oncomine database analysis. The Oncomine database (https://www. oncomine.org/resource/login.html) was screened for the expression of the TMC8 gene in several types of cancer. A threshold P-value of 0.001 and fold-change $\geq 2$ was used to assess statistical significance.
Gene Set Enrichment Analysis (GSEA). To identify potential biological mechanism of TMC8, GSEA was conducted to detect whether a previously defined set of genes showed statistically significant differential expression. Firstly, the TMC8 high expression group was selected based on the median expression (cut-off value 0.453101463 ) of TMC8, and the genes are sorted according to expression differences to form a gene list. The annotated gene sets C2.CP (186 gene sets) and C5.BP (5,910 gene sets) MSigDB datasets from the Broad Institute (https://www.gsea-msigdb.org/gsea/msigdb/index.jsp) were selected as the reference gene sets. These preset gene sets represented different biological processes or signal pathways. Then the GSEA algorithm could determine whether the members of this reference gene set were randomly distributed in the TMC8 high expression group gene list, or were mainly enriched at the front or end sides of the list. The third step was to calculate the enrichment score of the gene set and perform a permutation test of significance to obtain the P-value and the false discovery rate (FDR). FDR $<25 \%$ and $\mathrm{P}<0.05$ in the enrichment of MSigDB Collection (c2.cp.kegg.v6.2.symbols) were considered to be significantly enriched.

Tumor Immune Estimation Resource (TIMER) database analysis. The TIMER database can be used as a comprehensive resource for systematically analyzing immune infiltrates between several types of cancer (https://cistrome. shinyapps. io/timer/). Multiple deconvolution algorithms including TIMER (32), CIRBSORT (33) and xCell (34) are used to analyze the expression of TMC8 and the degree of infiltration of immune cells, including i) $\mathrm{CD}^{+} \mathrm{T}$ cells; ii) $\mathrm{CD}^{+} \mathrm{T}$ cells; iii) B cells; iv) dendritic cells (DCs); v) neutrophils; and vi) macrophages and their subgroups. The correlation between the infiltration levels of above-mentioned immune cells and the expression of TMC8 was obtained. 
Co-expression analysis in cBioPortal. For cancer genomics, cBioPortal (https://www.cbioportal.org) is an open-access, open-source resource for the interactive exploration of multidimensional cancer genomics data sets. The correlation between the hub gene expression and gene markers of immune cells were explored. The gene markers of the immune cells included markers of: i) $\mathrm{CD}^{+} \mathrm{T}$ Cells; ii) $\mathrm{T}$ cells (general); iii) B cells; iv) monocytes; v) tumor-associated macrophages (TAMs); vi) M1 macrophages; vii) M2 macrophages; viii) neutrophils; ix) natural killer (NK) cells; x) DCs; xi) T helper (Th)-1 cells; xii) Th2 cells; xiii) follicular helper T (Tfh) cells; xiv) Th17 cells; $\mathrm{xv}$ ) regulatory $\mathrm{T}$ cells ( $\mathrm{T}$ regs); and $\mathrm{xvi}$ ) exhausted $\mathrm{T}$ cells (34). Spearman's rank correlation coefficient method was used to identify the correlation coefficient.

Prognostic analysis of pan-cancers. Kaplan-Meier plotter (http://kmplot.com/analysis/) is capable of assessing the effect of 54,000 genes on survival in 21 types of cancer (35). The association between the hub gene expression and survival in all 21 types of cancer were analyzed using Kaplan-Meier plotter. All possible cut-off values between the lower and upper quartiles were computed and the best performing threshold was used as a cut-off value. The hazard ratio (HR) with $95 \%$ confidence intervals $(\mathrm{CI})$ and log-rank P-value were also calculated.

Statistical analysis. Survival curves were created using GEPIA and Kaplan-Meier plots. Three independent repeated unpaired and paired t-tests were carried out in GraphPad Prism (GraphPad Software, Inc. version 7.04) and R software (30) (version 3.5.3), and the results were shown as mean \pm standard deviation. The Oncomine results were presented with P-values, fold-changes and ranks. The Kaplan-Meier plots and GEPIA results were displayed with the HR and P-values obtained using log-rank tests. Correlation between TMC8 expression and the clinicopathological characteristics were analyzed using logistic regression. Potential prognostic factors were determined with a univariate Cox analysis and the associations between TMC8 expression and survival in conjunction with other clinical features were verified with a multivariate Cox analysis. $\mathrm{P}<0.05$ was considered to indicate a statistically significant difference.

\section{Results}

Expression of TMC8 in oral cancer specimens and adjacent normal tissue. HNSC specimens from 25 patients were analyzed in the present study, including 17 males and 8 females. The age of this group ranged from 43 to 81 years with a median age of 67. Immunohistochemical staining of OSCC tissue specimens and adjacent normal tissues revealed that TMC8 was strongly stained in tumor tissues, but the staining intensity was lower in adjacent tissues (Fig. 2A-D).

Expression of TMC8 is increased in oral cancer cell lines. Fig. 2E shows that, compared with $\mathrm{HOK}$, the expression levels of TMC8 in SCC9, SCC15, SCC25 and CAL27 cell lines were significantly upregulated.

TMC8 is upregulated in HNSC of TCGA data. As shown in Fig. 3A, TMC8 expression was higher in colorectal, breast and head and neck cancer compared with that of normal tissues. However, lower TMC8 expression was also observed in colorectal and breast cancer in addition to lung, leukemia and lymphoma cancer in some data sets. The differential level of TMC8 expression between tumor and normal tissues in HNSC for TCGA data is shown in Fig. 3B and C. The results indicated that TMC8 was overexpressed in HNSC samples $(\mathrm{P}<0.001)$ and paired samples $(\mathrm{P}<0.05)$.

Methylation analysis. In order to explore the possible reasons for the upregulation of TMC8 in HNSC, the relationship between its methylation status and its expression was further analyzed. Overall, 26 methylation sites out of a total of 31 were found to be significantly hypomethylated. Among them, cg00447208, cg01246266, cg03190661, cg08470991, cg19056418 and cg20943461, which were all located in the promoter region, showed significantly decreased levels of methylation in HNSC compared with normal samples. Additionally, they were significantly negatively correlated with the expression of TMC8 (all $\mathrm{P}<0.05$ ). The relationship between methylation sites and expression of TMC8 is shown in Table I.

Association with TMC8 expression and clinicopathologic variables. As shown in Table II, the increased expression of TMC8 was significantly correlated with the tumor origin (oropharynx vs. oral cavity; $\mathrm{P}=0.003$ ), histological grade (G3/G4 vs. G1/G2; P=0.04), HPV infection status (positive vs. negative; $\mathrm{P}=0.001$ ), immune-score (high vs. low, $\mathrm{P}<0.001$ ), as well as the stromal-score (high vs. low; $\mathrm{P}<0.001$ ). However, no significant differences between TMC8 expression and i) age; ii) alcohol use; iii) metastasis; iv) lymph node infiltration; v) $\mathrm{T}$ classification; vi) clinical stage; vii) lymphovascular invasion; viii) perineural invasion; or ix) nodal extra-capsular spread were observed.

Survival outcomes and multivariate analysis. As shown in Fig. 4A, the analysis of HNSC cases in TCGA showed that the 5-year OS time of the TMC8-high group was significantly greater compared with that of the low-expression group $(\mathrm{P}<0.05)$. Fig. 4B-H further shows the relationship between TMC8 expression and clinical features. In the cases of histopathological grade II-III and clinical stage III-IV, overexpression of TMC8 was significantly correlated with improved OS time. This result suggested that in advanced HNSC cases, high expression of TMC8 may improve the prognosis.

Univariate analysis (Table III) revealed that TMC8overexpression was significantly associated with an improved OS time (HR: 0.80; 95\% CI: 0.70-0.90; $\mathrm{P}=0.003$ ). Other clinicopathological variables were associated with increased survival including advanced age, positive marginal status, B cell infiltration and immune score. In the multivariate analysis, TMC8 remained independently associated with OS, with an HR of 0.80 (CI: $0.68-0.95 ; \mathrm{P}=0.01$ ), In conjunction with the advanced age, clinical stage and positive marginal status.

GSEA identifies a TMC8-associated signaling pathway. TMC8-associated pathway enrichment analysis results showed that 28 gene sets were significantly enriched when the adjusted P-value was $<5 \%$. As shown in Table IV, the following 

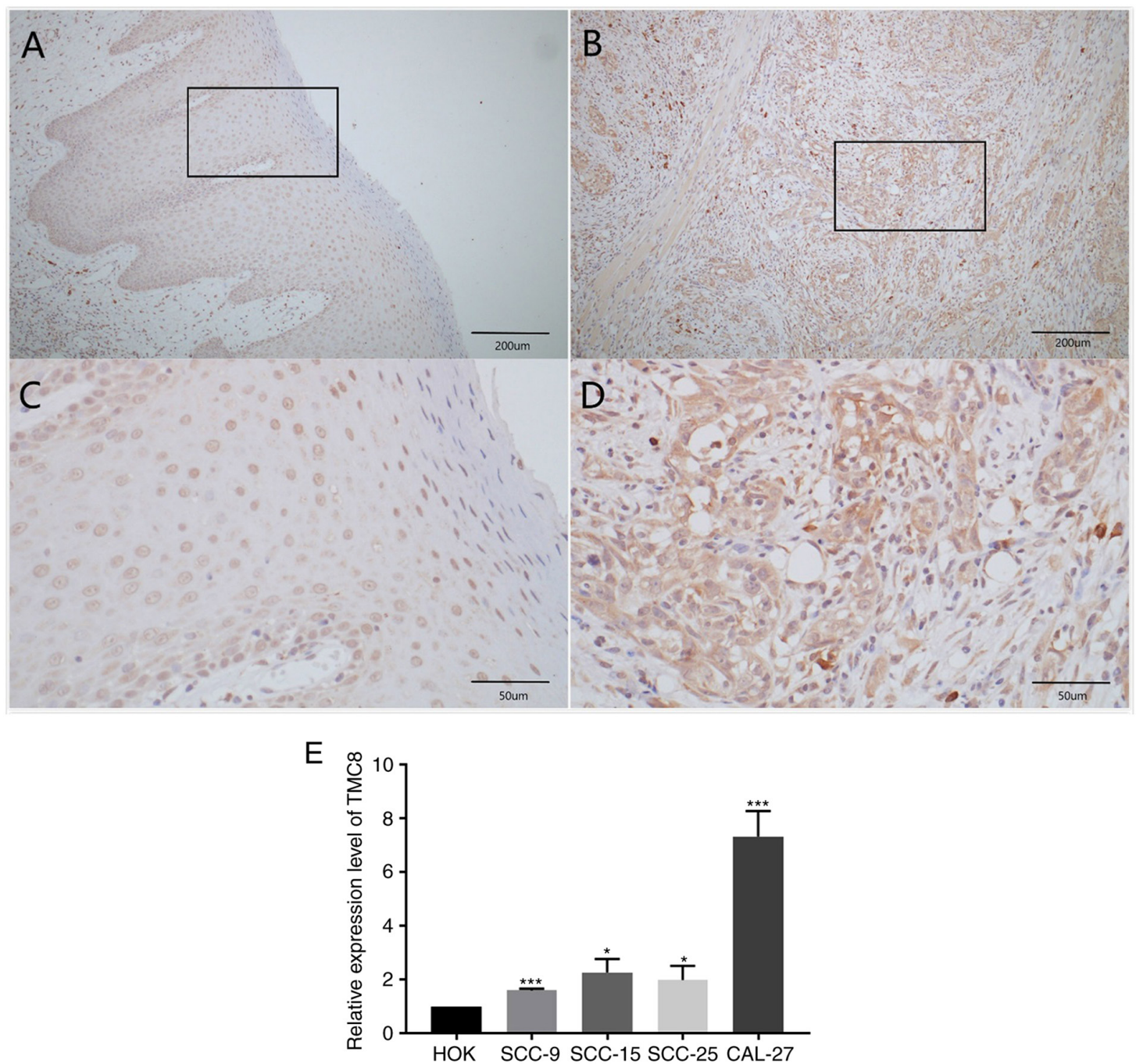

Figure 2. TMC8 is upregulated in OSCC. Representative immunohistochemical staining performed for detecting the expression of TMC8 from tumor-tissue specimens and adjacent normal tissues of patients with OSCC. (A and B) Normal mucosal epithelial cells, lightly stained with TMC8 antibody. (magnification, x100 or 400, respectively). (C and D) Oral cancer mucosal epithelial cells, lightly stained with TMC8 antibody. (magnification, x100 or 400, respectively). (E) Compared with HOK, the expression levels of TMC8 in SCC9, SCC15, SCC25 and CAL27 cell lines were significantly upregulated. * $<<0.05$ and ${ }^{* * *} \mathrm{P}<0.001$ vs. HOK. TMC8, transmembrane channel-like 8; OSCC, oral squamous cell carcinoma; HOK, human oral keratinocyte.

immune-associated biological processes are enriched in response to the increased TMC8 phenotype: i) 'Intestinal immune network for IgA production'; ii) 'primary immunodeficiency'; iii) 'leishmania infection'; iv) 'cytokine-cytokine receptor interaction'; v) 'natural killer cell-mediated cytotoxicity'; vi) 'hematopoietic cell lineage'; vii) 'autoimmune thyroid disease'; viii) 'T cell receptor signaling pathway'; ix) 'antigen processing and presentation'; and x) 'cell-adhesion molecules'. These signaling pathways may be the mechanisms involved in TMC8 function.

Relationship between TMC8 and immune cells infiltration. There was a significant negative correlation between TMC8 expression and tumor purity (Fig. 5A). In addition, the level of TMC8 expression was significant correlated with high levels of $\mathrm{CD}^{+} \mathrm{T}$ cell and $\mathrm{CD}^{+} \mathrm{T}$ cell infiltration in HNSC. Similarly, there were weak to moderate positive correlations with the level of infiltrating lymphocytes in HPV-positive HNSC samples, as well as in HPV-negative HNSC samples (correlation coefficient 0.142 to 0.639 , all $\mathrm{P}<0.05$; Fig. $\mathrm{B}$ and $\mathrm{C}$ ).
To avoid bias, the results of six other algorithms were listed, each of which provided the correlation coefficient between infiltration of different subsets of immune cells and expression of TMC8. As shown in Table V, different algorithms acquired similar results. TMC8 was positively correlated with T cell subsets, such as Th1, Th17, T regs and Tfh.

TMC8 expression and immune marker correlation analysis. To further verify the relationship between TMC8 and immune cells, the correlation between marker genes and TMC8 expression in different cells was calculated. As shown in Fig. 6A-C, TMC8 is strongly correlated with T cell (general) marker genes, including CD3D, CD3E and CD2 (all coefficients $>0.6$ and $\mathrm{P}<0.05$ ). TMC 8 was significantly correlated with marker genes of $\mathrm{CD}^{+}$cells (all $\mathrm{P}<0.05$ and coefficients $>0.3$; Fig. $6 \mathrm{D}-\mathrm{F}$ ) and B cells (all coefficients $>0.4$ and $\mathrm{P}<0.05$; Fig. 6G-I). In addition, the level of expression for a majority of markers on M1 (nitric oxide synthase 2 and interferon regulatory factor 5), M2 macrophages (CD163, $\mathrm{V}$-set and immunoglobulin domain-containing protein 4 and 
A

\begin{tabular}{|l||l|l|}
\hline Disease summary for TMC8 \\
\hline Analysis type by cancers & $\begin{array}{c}\text { Cancer } \\
\text { vs. } \\
\text { normal }\end{array}$ \\
\hline Bladder cancer & & \\
\hline Brain and CNS cancer & & \\
\hline Breast cancer & 1 & 1 \\
\hline Cervical cancer & & \\
\hline Colorectal cancer & 2 & 1 \\
\hline Esophageal cancer & & \\
\hline Gastric cancer & & \\
\hline Head and neck cancer & 1 & \\
\hline Kidney cancer & & \\
\hline Leukemia & & 1 \\
\hline Liver cancer & & \\
\hline Lung cancer & & 1 \\
\hline Lymphoma & & 1 \\
\hline Melanoma & & \\
\hline Myeloma & & \\
\hline Other cancer & \\
\hline Ovarian cancer & \\
\hline Pancreatic cancer & & \\
\hline Prostate cancer & & \\
\hline Sarcoma & \\
\hline Significant unique analysis & \\
\hline Total unique analysis & 5 & 5 \\
\hline & 266 \\
\hline
\end{tabular}

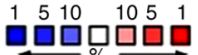

B

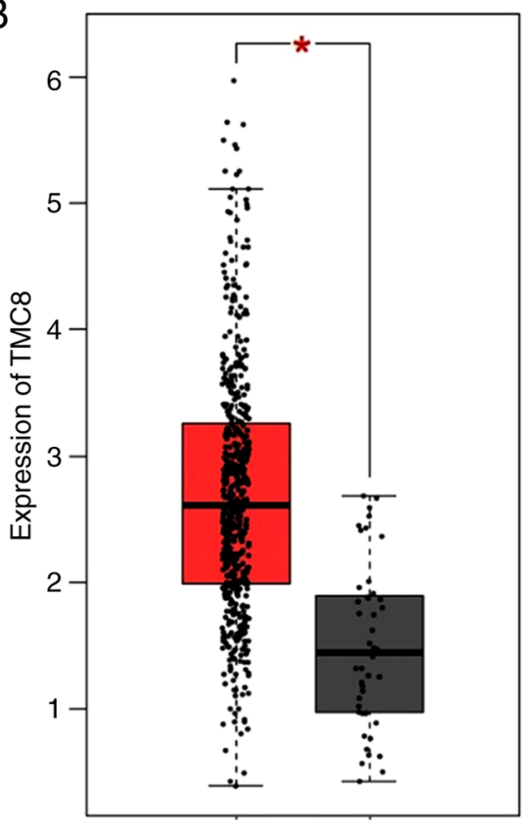

HNSC $(n=519)$ Normal $(n=44)$
C

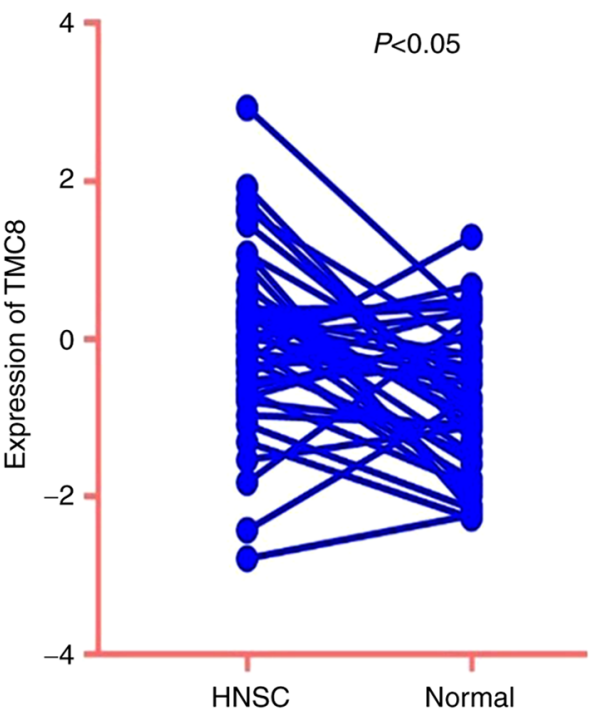

Paired samples $(n=44)$

Figure 3. Levels of TMC8 expression in HNSC and other types of cancer. (A) Increased or decreased TMC8 expression in datasets of different types of cancer in the Oncomine database. Cell color is determined by the best gene rank percentile for the analyses within the cell. Blue indicates that TMC8 gene expression is downregulated and red indicates that the gene is upregulated. (B) TMC8 expression was compared between normal tissues and HNSC tissues based on The Cancer Genome Atlas database. (C) Levels of TMC8 expression was compared in the paired samples. "P<0.05 vs. HNSC. HNSC, head and neck squamous cancer; TMC8, transmembrane channel-like 8 .
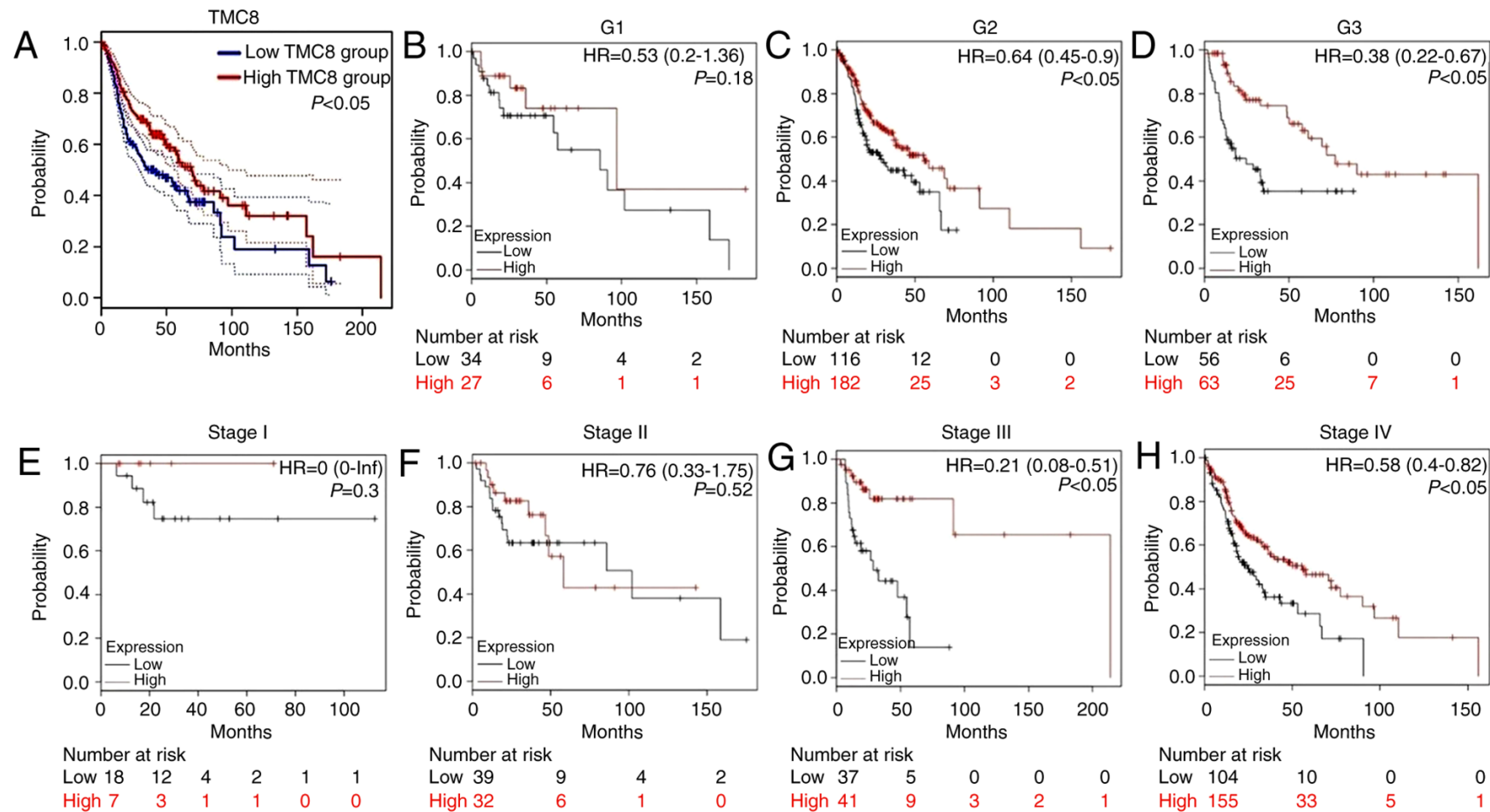

Figure 4. Relationship between the level of TMC8 expression and OS time. (A) Patients with high expression of TMC8 had better prognosis. (B-D) Kaplan-Meier curves for OS time in HNSC cases of histological grades G1, G2 and G3. (E-H) Kaplan-Meier curves for OS time in HNSC cases of clinical stages I-IV. HNSC, head and neck squamous cell cancer; OS, overall survival; TMC8, transmembrane channel-like 8; HR, hazard ratio.

membrane-spanning 4-domains subfamily A member 4A), TAMs (C-C motif chemokine 2, CD68 and interleukin 10), monocytes, DCs (human leukocyte antigen [HLA]-DPB1, HLA-DRA and HLA-DPA1) and other subclasses of T cells 
Table I. Relationship between methylation sites and expression of transmembrane channel-like 8 .

\begin{tabular}{|c|c|c|}
\hline Methylation site & Cor. & P-value \\
\hline $\operatorname{cg} 00447208^{\mathrm{a}}$ & -0.24 & $5.79 \times 10^{-08}$ \\
\hline $\operatorname{cg} 01246266^{\mathrm{a}}$ & -0.16 & $2.63 \times 10^{-04}$ \\
\hline $\operatorname{cg} 03190661^{\mathrm{a}}$ & -0.26 & $3.10 \times 10^{-09}$ \\
\hline $\operatorname{cg} 08470991^{\mathrm{a}}$ & -0.19 & $1.74 \times 10^{-05}$ \\
\hline $\operatorname{cg} 19056418^{a}$ & -0.28 & $1.39 \times 10^{-10}$ \\
\hline $\operatorname{cg} 20943461^{\mathrm{a}}$ & -0.31 & $1.73 \times 10^{-12}$ \\
\hline $\operatorname{cg} 01125010$ & 0.13 & $2.20 \times 10^{-03}$ \\
\hline cg01791634 & -0.18 & $4.01 \times 10^{-05}$ \\
\hline cg02909991 & -0.17 & $6.01 \times 10^{-05}$ \\
\hline cg02911077 & -0.20 & $4.09 \times 10^{-06}$ \\
\hline $\operatorname{cg} 03596178$ & 0.06 & 0.21 \\
\hline $\operatorname{cg} 03742808$ & -0.24 & $5.20 \times 10^{-08}$ \\
\hline $\operatorname{cg} 04947157$ & -0.24 & $3.02 \times 10^{-08}$ \\
\hline $\operatorname{cg} 05637296$ & -0.29 & $2.67 \times 10^{-11}$ \\
\hline $\operatorname{cg} 06248406$ & -0.04 & 0.35 \\
\hline cg06643271 & -0.17 & $1.16 \times 10^{-04}$ \\
\hline $\operatorname{cg} 08852879$ & 0.09 & 0.04 \\
\hline $\operatorname{cg} 09413013$ & -0.10 & 0.03 \\
\hline $\operatorname{cg} 11493223$ & -0.18 & $2.17 \times 10^{-05}$ \\
\hline $\operatorname{cg} 12798338$ & -0.24 & $5.76 \times 10^{-08}$ \\
\hline $\operatorname{cg} 14210726$ & 0.29 & $1.72 \times 10^{-11}$ \\
\hline $\operatorname{cg} 16214492$ & -0.23 & $8.22 \times 10^{-08}$ \\
\hline $\operatorname{cg} 16301617$ & -0.26 & $3.79 \times 10^{-09}$ \\
\hline $\operatorname{cg} 16935597$ & -0.16 & $1.55 \times 10^{-04}$ \\
\hline $\operatorname{cg} 18901278$ & -0.17 & $6.72 \times 10^{-05}$ \\
\hline $\operatorname{cg} 21282054$ & -0.26 & $1.11 \times 10^{-09}$ \\
\hline $\operatorname{cg} 22563987$ & 0.13 & $4.16 \times 10^{-03}$ \\
\hline $\operatorname{cg} 22833809$ & -0.16 & $2.60 \times 10^{-04}$ \\
\hline $\operatorname{cg} 24109860$ & -0.06 & 0.17 \\
\hline $\operatorname{cg} 24988684$ & -0.24 & $3.65 \times 10^{-08}$ \\
\hline cg26003388 & -0.22 & $4.63 \times 10^{-07}$ \\
\hline
\end{tabular}

${ }^{\text {aPromoter. }}$

were significantly correlated with TMC8 expression, details shown in Table SI.

Prognostic analysis of TMC8 on pan-cancers. As shown in Fig. 7, in five types of tumors: i) Bladder cancer; ii) cervical squamous cell carcinoma; iii) pheochromocytoma and paraganglioma; iv) sarcoma; and v) thymoma, high expression of TMC8 predicted a significantly increased OS time and improved prognosis (all $\mathrm{P}<0.05$ ).

\section{Discussion}

The present study analyzed the levels of TMC8 expression in HNSC and its prognostic association. The expression of TMC8 was upregulated in patients with HNSC and the methylation level in the promoter was significantly lower compared with that in normal tissues, which may be the reason for the change in TMC8 expression. The increased expression level of TMC8 in HNSC was further validated using tissue specimens. GSEA analysis was used to clarify the function of TMC8 and the results showed that it was involved in immune-associated pathways.

TMC8 expression was found to be significantly positively correlated with the infiltration of $\mathrm{CD}^{+} \mathrm{T}$ cells, $\mathrm{CD} 8^{+} \mathrm{T}$ cells, $\mathrm{B}$ cells, macrophages and DCs and their respective subgroups. These results indicated that TMC8 may enhance the infiltration of cytotoxic $\mathrm{T}$ cells and $\mathrm{B}$ lymphocytes by affecting $\mathrm{CD} 4^{+} \mathrm{T}$ cells. Finally, the impact of TMC8 on the prognosis of various malignancies was evaluated and the results showed that TMC8 could significantly affect the OS of various types of cancer, including HNSC. The findings of the present study showed that TMC8, as one of the genes involved in HPV immune responses (36) may play a very complex role in the immune network and ultimately inhibit the development of tumors.

The relationship between HPV and skin malignancies has been found in patients with EV (37). These patients usually develop invasive skin squamous cell carcinoma (38). In a previous study (38) germline mutations of two genes, EVER1 and EVER2, also known as TMC6 and TMC8, were found in patients with EV. The inability of patients with EV to effectively clear HPV from their own skin is mainly due to cell-mediated immunodeficiency (39). Defects in the TMC8 gene have been previously suggested to promote an environment favorable to HPV replication in addition to the persistence of skin cancer-prone lesions (23). A study investigating a common polymorphism (rs7208422) in the TMC8 gene in patients with skin cancer has found that the polymorphism is not only associated with positive serological tests for skin HPV types, but also with an increased risk of skin squamous cell carcinoma (40). In the present study, TMC8 was found to be highly expressed in HNSC. At present, no study has been conducted to detect the changes in the expression level of TMC8 in HNSC, to the best knowledge of the authors. Two previous studies have revealed that common single nucleotide polymorphisms in TMC8 increase the risk of HNSC $(36,41)$. In the current study, the TIMER algorithm showed a negative correlation between TMC8 expression and tumor purity, suggesting that TMC8 was expressed more frequently in tumor-infiltrating lymphocytes and mesenchymal cells compared with in squamous cancer cells. The mesenchymal cells around the tumor mainly include immune cells, for example, macrophages, $\mathrm{T}$ cells and neutrophils (42). Previously published data indicate that TMC8 is highly expressed in various types of hematopoietic cells, including $\mathrm{CD}^{+}{ }^{+}$and $\mathrm{CD}^{+}{ }^{+} \mathrm{T}$ lymphocytes, $\mathrm{B}$ cells and NK cells $(25,26,43)$. Therefore, the high expression of TMC8 in mesenchymal cells may contribute to its upregulation in HNSC. To determine whether TMC8 is highly expressed in tumor cells, immunohistochemical staining and detection of TMC8 expression in SCC cell lines using qPCR was used in the present study. These results confirmed that TMC8-upregulation was not only due to the enrichment of T cells in tumor stroma, but also synchronously upregulated in tumor cells as the SCC cell line tested by qPCR avoids the interstitial cells contained in the tumor tissue.

The present study then explored the underlying causes of the observed transcriptional changes and focused on the 
Table II. Correlation between TMC8 expression and the clinicopathological characteristics of patients with head and neck squamous cancer (logistic regression).

\begin{tabular}{|c|c|c|c|}
\hline Clinical characteristics & Total, $\mathrm{n}$ & $\begin{array}{c}\text { Odds ratio in TMC8 } \\
\text { expression hazard ratio }(\mathrm{CI})\end{array}$ & P-value \\
\hline Age, continuous & 520 & $1.01(0.99-1.02)$ & 0.23 \\
\hline Drinking, yes vs. no & 509 & $0.96(0.65-1.43)$ & 0.84 \\
\hline Smoke, yes vs. no & 520 & $1.10(0.78-1.56)$ & 0.60 \\
\hline Tumor origin, oropharynx vs. oral cavity & 520 & $1.74(1.20-2.51)$ & $3.20 \times 10^{-3 a}$ \\
\hline Distance metastasis, positive vs. negative & 496 & $0.94(0.51-1.74)$ & 0.85 \\
\hline Lymph nodes, positive vs. negative & 498 & $0.82(0.58-1.17)$ & 0.28 \\
\hline T classification, T1/T2 vs. T3/T4 & 504 & $0.71(0.49-1.02)$ & 0.07 \\
\hline Stage, I/II vs. III/IV & 506 & $0.75(0.28-1.98)$ & 0.57 \\
\hline HPV, positive vs. negative & 121 & $3.98(1.78-9.39)$ & $1.10 \times 10^{-3 a}$ \\
\hline Lymphovascular invasion, positive vs. negative & 348 & $1.39(0.89-2.16)$ & 0.15 \\
\hline Perineural invasion, positive vs. negative & 362 & $0.75(0.49-1.13)$ & 0.17 \\
\hline Nodal extracapsular spread, positive vs. negative & 356 & $0.77(0.49-1.21)$ & 0.25 \\
\hline Histological grade, G3/G4 vs. G1/G2 & 498 & $1.51(1.02-2.27)$ & 0.04 \\
\hline Immune score, high vs. low & 520 & $5.17(3.57-7.55)$ & $6.81 \times 10^{-18 a}$ \\
\hline Stromal score, high vs. low & 520 & $1.95(1.38-2.77)$ & $1.72 \times 10^{-4 a}$ \\
\hline
\end{tabular}

${ }^{\text {aP }}<0.05$. TMC8, transmembrane channel-like 8; CI, confidence interval.

Table III. Univariate and multivariate analyses of OS time using the Cox proportional hazard regression model ( $\mathrm{n}=415$ ).

\begin{tabular}{|c|c|c|c|c|c|c|}
\hline \multirow[b]{2}{*}{ Parameter } & \multicolumn{3}{|c|}{ Univariate analysis } & \multicolumn{3}{|c|}{ Multivariate analysis } \\
\hline & HR & CI, $95 \%$ & P-value & HR & CI, $95 \%$ & P-value \\
\hline Age & 1.02 & $1.01-1.04$ & $9.94 \times 10^{-4 a}$ & 1.02 & $1.006-1.035$ & $4.00 \times 10^{-3 \mathrm{a}}$ \\
\hline Alcohol-use & 0.96 & $0.71-1.29$ & 0.77 & 1.03 & $0.741-1.425$ & 0.87 \\
\hline Sex & 0.81 & $0.59-1.10$ & 0.18 & 0.87 & $0.614-1.222$ & 0.41 \\
\hline Clinical stage & 1.32 & $0.93-1.88$ & 0.12 & 1.45 & $1.005-2.078$ & $0.47 \times 10^{-2 \mathrm{a}}$ \\
\hline Margin status & 1.61 & $1.11-2.34$ & $0.01^{\mathrm{a}}$ & 1.69 & $1.146-2.480$ & $0.01^{\mathrm{a}}$ \\
\hline Histological grade & 1.08 & $0.78-1.49$ & 0.63 & 1.24 & $0.881-1.752$ & 0.22 \\
\hline B cell & 0.09 & $0.01-0.64$ & $0.02^{\mathrm{a}}$ & 0.16 & $0.011-2.298$ & 0.18 \\
\hline $\mathrm{CD}^{+}{ }^{\mathrm{T}}$ cell & 0.28 & $0.05-1.61$ & 0.16 & 0.03 & $0.008-7.332$ & 0.42 \\
\hline $\mathrm{CD}^{+} \mathrm{T}$ cell & 0.55 & $0.20-1.49$ & 0.24 & 0.77 & $0.130-4.509$ & 0.77 \\
\hline Neutrophil & 0.81 & $0.15-4.52$ & 0.81 & 3.93 & $0.229-67.382$ & 0.35 \\
\hline Macrophage & 1.43 & $0.32-6.39$ & 0.64 & 3.49 & $0.328-36.985$ & 0.30 \\
\hline Dendritic cell & 0.88 & $0.47-1.66$ & 0.70 & 3.75 & $0.745-18.908$ & 0.11 \\
\hline Immune-score & 1.00 & $9.998 \times 10^{-3}-9.99 \times 10^{-3}$ & $0.04^{\mathrm{a}}$ & 1.00 & $9.997 \times 10^{-3}-1.000 \times 10^{-3}$ & 0.14 \\
\hline Stromal-score & 1.00 & $9.998 \times 10^{-3}-1.000 \times 10^{-3}$ & 0.13 & 1.00 & $9.999 \times 10^{-3}-1.000 \times 10^{-3}$ & 0.15 \\
\hline TMC8 & 0.80 & $0.70-0.90$ & $3.00 \times 10^{-4 a}$ & 0.80 & $0.68-0.95$ & $0.0^{1 \mathrm{a}}$ \\
\hline
\end{tabular}

${ }^{\mathrm{a}}<0.05$. TMC8, transmembrane channel-like 8 .

frequency of methylation changes. The downregulation of gene expression caused by hypermethylation of $\mathrm{CpG}$ islands in gene promoter regions is a common gene silencing mechanism in epigenetic regulation (44). A total of six methylation sites of TMC8 located in the promoter region showed significant hypomethylation in patients with HNSC, which was a notable reason for TMC8-downregulation. The DNA modification of different structural elements, such as the promoter, coding region or distal enhancer region of the gene, as well as the combined action of transcription factors and microRNA, constitute a complex regulatory system for gene transcription $(45,46)$. Whether other epigenetic modifications, such as 
Table IV. Gene sets enriched analysis of upregulated TMC8 in head and neck squamous cancer.

\begin{tabular}{lcc}
\hline Gene sets & NES & Adjusted P-value \\
\hline Intestinal immune network for IgA production & 2.19 & 0.01 \\
Primary immunodeficiency & 2.13 & 0.01 \\
Leishmania infection & 2.08 & 0.01 \\
Cytokine-cytokine receptor interaction & 2.01 & 0.01 \\
Natural killer cell mediated cytotoxicity & 2.01 & 0.01 \\
Hematopoietic cell lineage & 2.01 & 0.01 \\
Autoimmune thyroid disease & 1.98 & 0.01 \\
T cell receptor signaling pathway & 1.99 & 0.01 \\
Antigen processing and presentation & 1.96 & 0.01 \\
Cell-adhesion molecules & 1.97 & 0.01 \\
Type I diabetes mellitus & 1.88 & 0.03 \\
Chemokine signaling pathway & 1.89 & 0.03 \\
Systemic lupus erythematosus & 1.86 & 0.03 \\
B cell receptor signaling pathway & 1.86 & 0.03 \\
Asthma & 1.85 & 0.03 \\
Tryptophan metabolism & 1.83 & 0.04
\end{tabular}

NES, normalized enrichment score.

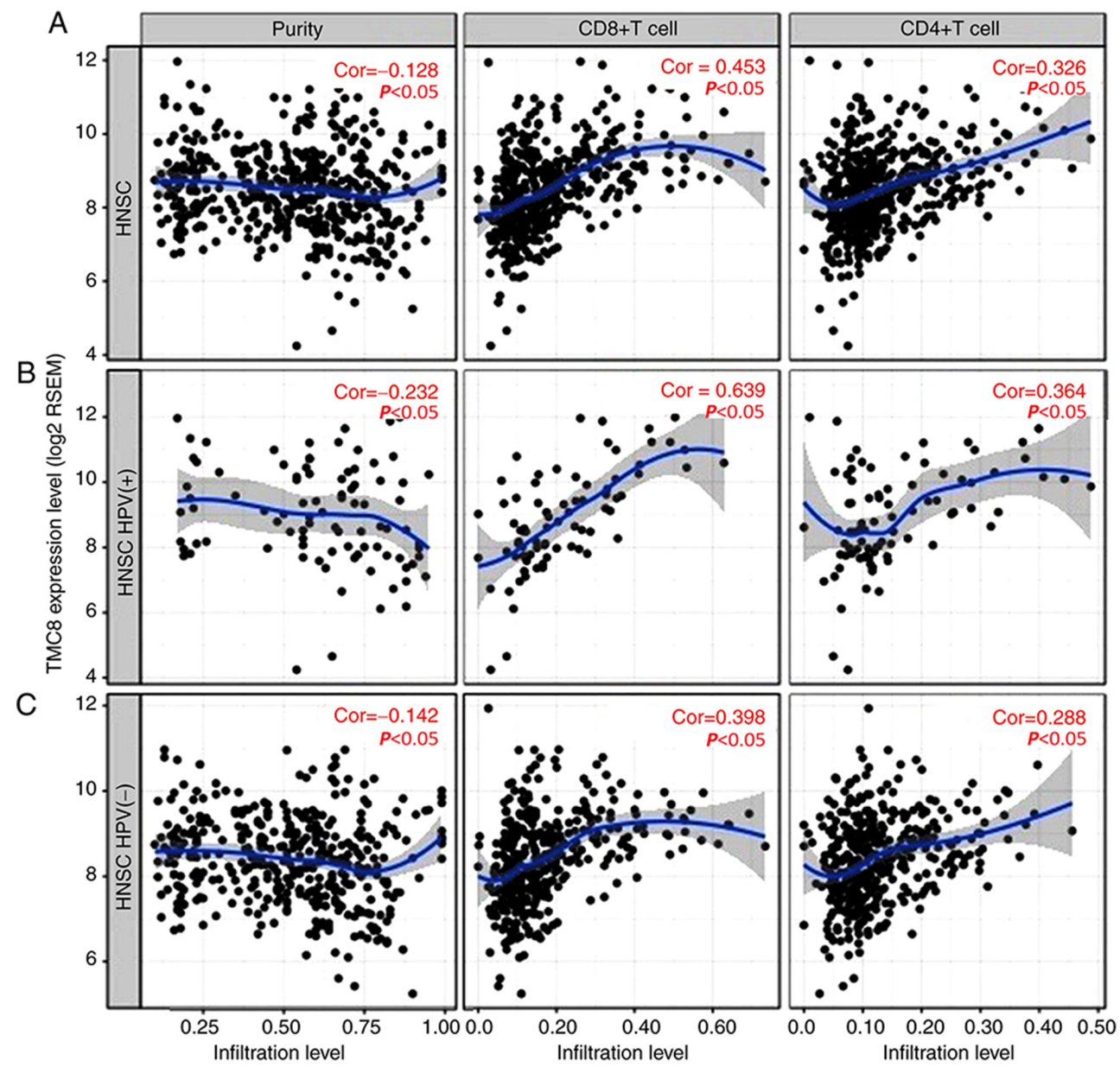

Figure 5. Correlation between the level of TMC8 expression and T lymphocyte infiltration in HNSC obtained from the Tumor Immune Estimation Resource database. (A) TMC8 expression was negatively correlated with tumor purity in HNSC, but was significantly positively correlated with infiltration of CD8 ${ }^{+}$ $\mathrm{T}$ cells and $\mathrm{CD} 4^{+} \mathrm{T}$ cells (all $\mathrm{P}<0.05$ ). (B and C) Similar positive correlations were observed with the level of infiltrating lymphocytes in both HPV-positive and -negative HNSC samples (all P<0.05). HNSC, head and neck squamous cancer; TMC8, transmembrane channel-like 8; Cor, correlation; HPV, human papillomavirus; RSEM, RNA sequencing by expectation-maximization. 
Table V. Relationship between transmembrane channel-like 8 and immune cell subgroups by different algorithm.

\begin{tabular}{|c|c|c|c|c|c|c|}
\hline \multirow[b]{2}{*}{ Subsets of immune cells } & \multicolumn{6}{|c|}{ Correlation coefficients } \\
\hline & CIBERSORT & Xcell & TISIDB & EPIC & MCPCOUNTER & QUANTISEQ \\
\hline $\mathrm{CD}^{+}{ }^{+} \mathrm{T}$ cell & - & - & - & - & - & - \\
\hline $\mathrm{CD}^{+}{ }^{+} \mathrm{T}$ cell & - & - & - & 0.18 & - & $-0.30^{\mathrm{a}}$ \\
\hline $\mathrm{CD}^{+}$naive & -0.17 & $0.37^{\mathrm{a}}$ & & - & - & - \\
\hline $\mathrm{CD}^{+} \mathrm{Th} 1$ & - & 0.13 & $0.42^{\mathrm{a}}$ & - & - & - \\
\hline $\mathrm{CD} 4^{+} \mathrm{Th} 2$ & - & 0.11 & 0.05 & - & - & - \\
\hline $\mathrm{CD}^{+}{ }^{+} \mathrm{Th} 17$ & - & - & $0.33^{\mathrm{a}}$ & - & - & - \\
\hline Tfh & $0.67^{\mathrm{a}}$ & - & $0.36^{\mathrm{a}}$ & - & - & - \\
\hline Treg & $0.44^{\mathrm{a}}$ & 0.16 & $0.26^{\mathrm{a}}$ & - & - & $0.52^{\mathrm{a}}$ \\
\hline $\mathrm{CD} 4^{+}$memory & - & $0.25^{\mathrm{a}}$ & - & - & - & - \\
\hline $\mathrm{CD}^{+}$memory resting & $0.22^{\mathrm{a}}$ & - & - & - & - & - \\
\hline $\mathrm{CD}^{+}$central memory & - & -0.10 & 0.04 & - & - & - \\
\hline $\mathrm{CD} 4^{+}$memory activated & $0.26^{\mathrm{a}}$ & - & - & - & - & - \\
\hline $\mathrm{CD}^{+}{ }^{+}$effector memory & - & 0.00 & 0.17 & - & - & - \\
\hline$\gamma \delta$ & 0.10 & 0.18 & - & - & - & - \\
\hline $\mathrm{CD}^{+} \mathrm{T}$ cell & - & - & - & - & - & - \\
\hline $\mathrm{T}_{\text {cell }} \mathrm{CD}^{+}$ & $0.60^{\mathrm{a}}$ & $0.41^{\mathrm{a}}$ & - & 0.13 & $0.58^{\mathrm{a}}$ & $0.54^{\mathrm{a}}$ \\
\hline $\mathrm{T}$ cell $\mathrm{CD}^{+}$naive & - & 0.02 & $0.50^{\mathrm{a}}$ & - & - & - \\
\hline $\mathrm{T}$ cell $\mathrm{CD}^{+}$central memory & - & $0.52^{\mathrm{a}}$ & -0.06 & - & - & - \\
\hline $\mathrm{T}$ cell $\mathrm{CD}^{+}$effector memory & - & $0.35^{\mathrm{a}}$ & - & - & - & - \\
\hline B cell & - & - & - & - & - & - \\
\hline $\mathrm{B}$ cell & - & - & - & $0.41^{\mathrm{a}}$ & $0.48^{\mathrm{a}}$ & $0.53^{\mathrm{a}}$ \\
\hline B cell naive & 0.21 & $0.27^{\mathrm{a}}$ & - & - & - & - \\
\hline B cell plasma & $0.24^{\mathrm{a}}$ & $0.25^{\mathrm{a}}$ & - & - & - & - \\
\hline B cell memory & $0.22^{\mathrm{a}}$ & $0.39^{\mathrm{a}}$ & 0.12 & - & - & - \\
\hline Macrophage & - & - & - & - & - & - \\
\hline Macrophage & - & $0.26^{\mathrm{a}}$ & $0.34^{\mathrm{a}}$ & $0.43^{\mathrm{a}}$ & $0.27^{\mathrm{a}}$ & - \\
\hline Macrophage M1 & $0.49^{\mathrm{a}}$ & $0.31^{\mathrm{a}}$ & - & - & - & 0.17 \\
\hline Macrophage M2 & $0.45^{\mathrm{a}}$ & 0.20 & - & - & - & $0.40^{\mathrm{a}}$ \\
\hline Dendritic cell & - & & - & - & - & - \\
\hline Myeloid dendritic cell & - & $0.33^{\mathrm{a}}$ & - & - & $0.51^{\mathrm{a}}$ & 0.08 \\
\hline Myeloid dendritic cell activated & -0.05 & $0.48^{\mathrm{a}}$ & $0.25^{\mathrm{a}}$ & - & - & - \\
\hline Myeloid dendritic cell resting & 0.19 & - & - & - & - & - \\
\hline NK cell & - & - & - & - & - & - \\
\hline NK cell & - & -0.13 & $0.34^{\mathrm{a}}$ & 0.19 & $0.52^{\mathrm{a}}$ & $0.32^{\mathrm{a}}$ \\
\hline NK cell resting & -0.09 & - & - & - & - & - \\
\hline NK cell activated & $0.37^{\mathrm{a}}$ & - & - & - & - & - \\
\hline Neutrophil & - & - & - & - & - & - \\
\hline Neutrophil & -0.09 & $0.22^{\mathrm{a}}$ & -0.05 & - & -0.03 & 0.06 \\
\hline Monocyte & - & - & - & - & - & - \\
\hline Monocyte & 0.11 & -0.02 & 0.19 & - & $0.27^{\mathrm{a}}$ & 0.11 \\
\hline Mast cell & - & - & & - & - & - \\
\hline Mast cell & - & -0.03 & $0.27^{\mathrm{a}}$ & - & - & - \\
\hline Mast cell resting & -0.10 & - & - & - & - & - \\
\hline Mast cell activated & $0.25^{\mathrm{a}}$ & - & - & - & - & - \\
\hline
\end{tabular}

${ }^{\mathrm{a}} \mathrm{P}<0.05$. Tfh, follicular T helper; Treg, regulatory $\mathrm{T}$ cell; $\mathrm{NK}$, natural killer T cell.

histone deacetylation or chromatin remodeling, affects the expression or function of TMC8 requires further study.
The relationship between TMC8 and lymphocytes is not completely clear. Research by Lazarczyk et al (25) showed that 

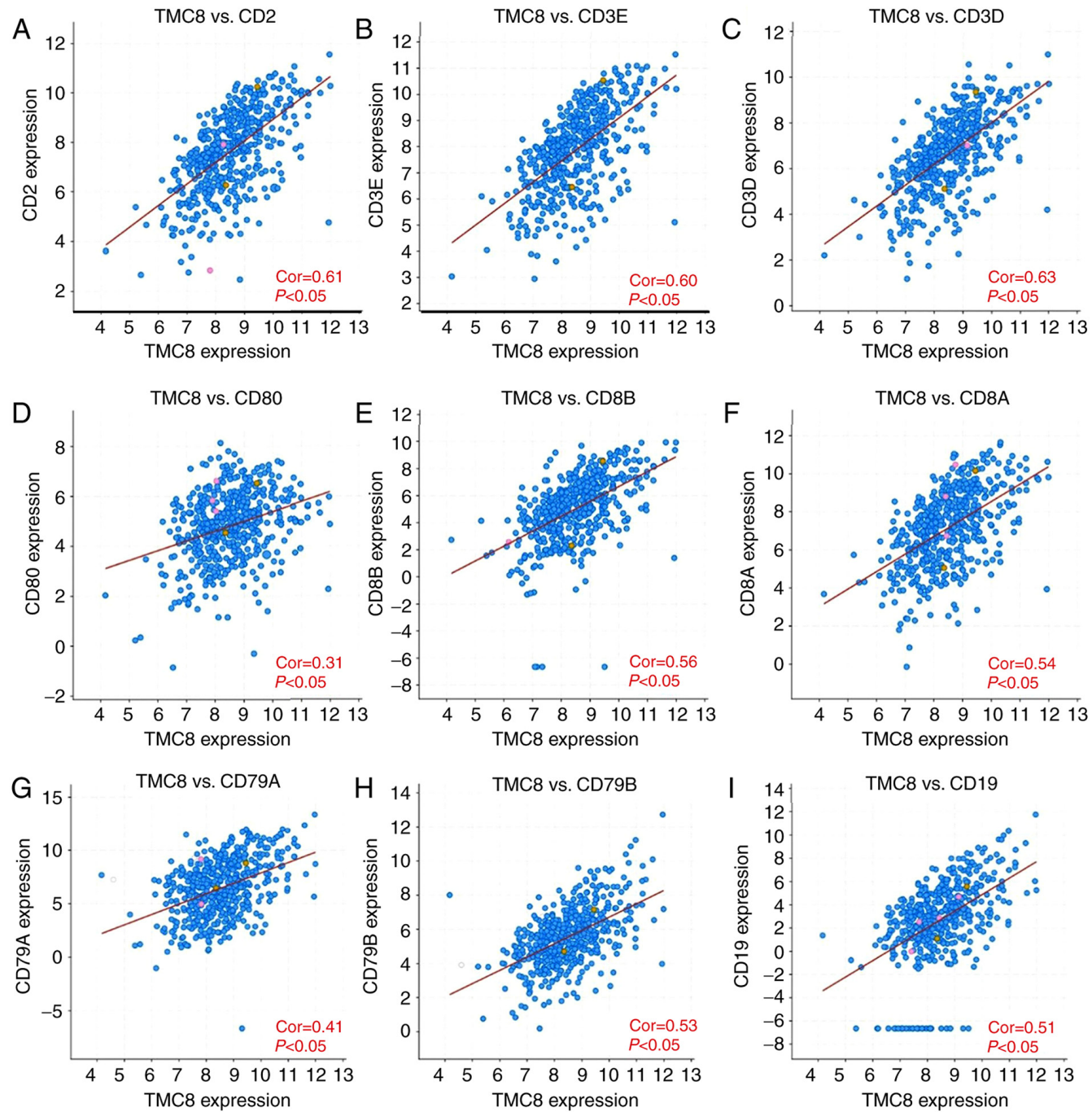

Figure 6. Correlation analysis between TMC8 and lymphocyte marker genes in cBioPortal. (A-C) T cell marker genes, including CD2, CD3E and CD3D, had a significant positive correlation with TMC8. (D-F) CD80, CD8B and CD8A are marker genes of CD8 ${ }^{+} \mathrm{T}$ cells. (G-I) Marker genes of B cells, including CD79A, CD79B and CD19, had a significant negative correlation with TMC8. TMC8, transmembrane channel-like 8; Cor, correlation.

TMC8 is also involved in the maintenance of lymphocyte zinc homeostasis. Moreover, mutations in the TMC8 gene result in an excess of zinc ions, which in turn blocks the activation and proliferation of T cells. Crequer et al (26) studied the lymphocytes of three adult patients with EV and TMC8 mutations and found that the number of $\mathrm{CD} 4^{+}$and $\mathrm{CD} 8^{+} \mathrm{T}$ cells and the response to stimulation were normal. However, the number of memory $\mathrm{CD}^{+} \mathrm{T}$ cells and effector memory $\mathrm{CD} 8^{+} \mathrm{T}$ cells increased significantly. This finding suggests that patients with TMC8 dysfunction have mild T cell dysfunction. The significant positive correlation between TMC8 and T cells is due to its high expression in $\mathrm{T}$ cells in the current study, which also shows that it can be used as an effective indicator of $\mathrm{T}$ cell infiltration and function. However, different subpopulations of lymphocytes exert different effects $(47,48)$, and whether the expression of TMC8 can reflect the enrichment of specific subpopulations has not yet been reported to the authors' knowledge. Therefore, the present study further explored the role of TMC8 in immune network through correlation analysis.

Various immune deconvolution methods (49) can be used to estimate the abundance of immune infiltrates, including
TIMER, CIBERSORT, quanTIseq, xCell, MCPCounter and EPIC methods. To avoid bias, multiple algorithms were used for cross-validation in the present study. The results showed that different algorithms had almost consistent results. The primary $\mathrm{CD}^{+}{ }^{+} \mathrm{T}$ cells differentiate into $\mathrm{Th} 1$ cells, Th2 cells, Th7 cells, $T$ reg cells and follicular helper $T$ cells under the action of different cytokines and transcription factors. Among them, the body's antitumor and anti-virus effect is dominated by Th1-mediated cellular immunity. IFN- $\gamma$ secreted by Th1 can significantly promote the expression level of MHC class I molecules in tumor cells, thereby activating the function of specific $\mathrm{CD}^{+} \mathrm{T}$ lymphocytes. IFN- $\gamma$ can also increase the phagocytic activity of macrophages and inhibit the formation of tumor blood vessels $(47,50)$. Previous research also shows that the Th1 cell immune response plays a very important role in controlling and eliminating HPV infection and determines the outcome of HPV infection $(51,52)$. In the current study, the expression of TMC 8 and Th1 infiltration were significantly positively correlated, suggesting that TMC8-upregulation is an important reference indicator of Th1 cell function. The expression of TMC8 in patients with HPV-positive HNSC was 

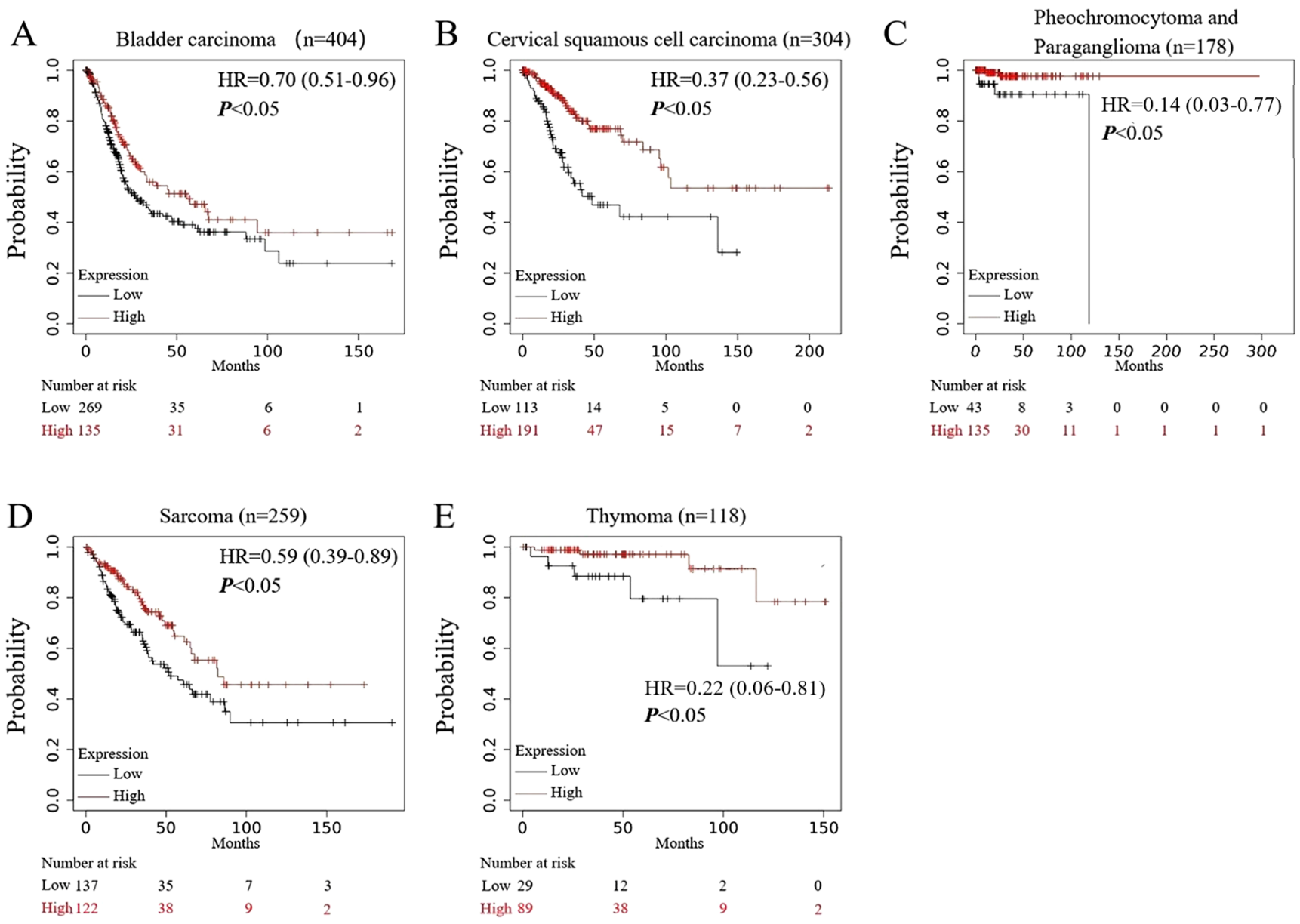

Figure 7. Prognostic analysis of TMC8 in multiple types of cancer. (A-E) In bladder carcinoma, cervical squamous cell carcinoma, pheochromocytoma and paraganglioma, sarcoma and thymoma, high expression of TMC8 was associated with good prognosis $\left(\mathrm{P}=2.7 \times 10^{-2}, \mathrm{P}=1.6 \times 10^{-5}, \mathrm{P}=8.2 \times 10^{-3}, \mathrm{P}=0.01\right.$ and $\mathrm{P}=1.3 \times 10^{-2}$, respectively). TMC8, transmembrane channel-like 8; HR, hazard ratio.

significantly upregulated compared with that of patients who were HPV-negative, suggesting that TMC8 may play the role of a HPV barrier through Th1 cells.

Tfh cells are key Th cells that can activate naive B cells to differentiate into plasma cells to produce antibodies and produce a humoral immune response (53). However, the direct effect of Tfh on tumors has not yet been clarified. At present, Tfh is closely associated with the etiology in angioimmunoblastic T-cell lymphoma (AITL) (54), peripheral T-cell lymphomas with follicular growth pattern (PTCL-F) (55) and B cell lymphoma 6 (BCL-6) (53). Th2 stimulates B cell proliferation by secreting interleukin (IL)-4, which mediates the humoral immune response (56). The current study showed that there was a significant positive correlation between TMC8 expression and Tfh, Th2 infiltration and B cell enrichment, suggesting that TMC8 may further regulate B cell activation through Tfh and Th2.

Th17 cells have opposite functions at different stages of the tumor. In the microenvironment of solid tumors, it exerts anticancer effects by secreting IL-17 $(57,58)$. However, as the tumor progresses, the infiltration of $\mathrm{T}$ reg cells will induce Th1 to secrete a large amount of IL-10 and promote tumor angiogenesis. The results of the present study indicated that in advanced HNSC (grades G3 and G4), TMC8 expression was upregulated, while TMC8 and Th17 were significantly co-expressed. This is consistent with the change of Th17 function, suggesting that TMC8 plays a complex role in the tumor microenvironment.

In addition to lymphocytes, TMC8 was also found to be significantly positively correlated with infiltration of mesenchymal cells, including macrophages and DCs. Macrophages account for $>50 \%$ of the tumor stroma (59). M1 and M2 macrophages play opposite roles in the tumor microenvironment (60), but TMC8 was upregulated in both types of macrophages, indicating that TMC8 is not involved in macrophage polarization. To further clarify the possible function of TMC8 expression in immunity, previously reported gene markers were compared. Co-expression of markers for TAMs, M1 phenotype and M2 phenotype with TMC8 remained consistent with the results of the previous algorithm results. DC markers also showed a significant correlation with TMC8 expression, indicating a close relationship between TMC8 and DC penetration. The combination of DC and T cells can secrete IL-12 and IL-18 to activate T cell proliferation, induce CTL production and the Th1 type immune response, which is conducive to tumor clearance (61). The co-expression of TMC8 and marker genes of specific immune cells further verified the results of the different immune algorithms.

Tumors of different cancer types may share underlying similarities (62). Thus, pan-cancer analysis of large-scale datasets has the potential to improve disease modeling by 
exploiting these similarities. In addition to HNSC, the results of the Kaplan-Meier database also showed that in bladder cancer, cervical squamous cell carcinoma, pheochromocytoma and paraganglioma, thymoma and sarcoma, TMC8-upregulation and improved OS time were significantly correlated. It was hypothesized that TMC8 was responsible for the resistance to HPV infection, thereby increasing cancer susceptibility. In the present study, TMC8-overexpression was associated with the improved prognosis of a variety of cancer types; however, the mechanism of how these different types of cancer are associated with HPV infection still needs further confirmation. In pathogen-associated human malignancies, up to $35 \%$ are caused by HPV and the carcinogenic potential of different HPV species varies widely (63). It is well known that cervical cancer and HNSC have also been shown to be associated with HPV infection (64). Studies have reported that mutations in TMC6 and TMC8 increases the risk of developing cervical cancer from persistent HPV infection $(24,65)$. Liang et al (36) reported that the common genetic variations in TMC8 are associated with the etiology of high-risk HPV infection and HNSC. These results show that the TMC8 gene is a key component of human keratinocyte HPV barrier that may affect the biological behavior of cells through immune-mediated pathways and ultimately affect disease prognosis. However, the opposite outcome was observed in other cancer types. Yamada et al (66) suggested that TMC8 is one of the numerous downstream genes of microRNA-144-5p/oncogenic syndecan-3 axes, which are associated with a poor prognosis of renal clear cell carcinoma. In addition, Lu et al (67). Reported that a higher level of TMC8 expression is associated with a poorer prognosis for hepatocellular carcinoma.

The present study had certain limitations. The correlation strength between TMC8 and the infiltration level of some immune cells was only weak to moderate. Further research, including deep sequencing, is needed to identify the full spectrum of variability and any functional variants of TMC8. It is also necessary to further explore the specific molecular mechanism of TMC8 in HNS carcinoma cells.

In summary, the present study reported that variations in the level of TMC8 expression correlated with HNSC prognosis. High levels of TMC8 expression were associated with improved OS time, which suggested that TMC8 expression could predict tumor prognosis. Furthermore, the findings demonstrated that the extent of immune cell infiltration and the diversity of immune marker expression were correlated with TMC8 expression in HNSC. Therefore, these results provided insight into the potential function of TMC8 in tumor immunology and its potential as a biomarker for HNSC.

\section{Acknowledgements}

Not applicable.

\section{Funding}

This study was supported by Shenzhen Healthcare Research Project (grant no. SZLY2018022), the Sanming Project of Medicine in Shenzhen (grant no. SZSM 201512036) and Shenzhen Fund for Guangdong Provincial High-level Clinical Key Specialties (grant no. SZGSP008).

\section{Availability of data and materials}

All data generated or analyzed during this study are included in this published article. Additional datasets generated and/or analyzed during the current study are available in the following repositories: The Cancer Genome Atlas (https://portal.gdc. cancer.gov), Gene Expression Profiling Interactive Analysis (http://gepia.cancer-pku.cn/index.html), Oncomine database (https://www. oncomine.org/resource/login.html) Tumor Immune Estimation Resource (https://cistrome. shinyapps. io/timer/), cBioPortal (https://www.cbioportal.org) and Kaplan-Meier plotter (http://kmplot.com/analysis/).

\section{Authors' contributions}

HYY and YHS designed the research and reviewed the writing. BL analyzed the data and prepared the original draft. SJW and YDY performed the statistical calculations and experiments. All authors read and approved the manuscript. BL and YHS confirmed the authenticity of all raw data.

\section{Ethics approval and consent to participate}

This study was approved by the Ethics Committee of Peking University Shenzhen Hospital (Shenzhen, China). Signed informed consent were obtained from the patients and/or guardians.

\section{Patient consent for publication}

Not applicable.

\section{Competing interests}

The authors declare that they have no competing interests.

\section{References}

1. Sanderson RJ and Ironside JA: Squamous cell carcinomas of the head and neck. BMJ 325: 822-827, 2002.

2. Chaturvedi AK, Anderson WF, Lortet-Tieulent J, Curado MP, Ferlay J, Franceschi S, Rosenberg PS, Bray F and Gillison ML: Worldwide trends in incidence rates for oral cavity and oropharyngeal cancers. J Clin Oncol 31: 4550-4559, 2013.

3. Leemans CR, Snijders PJF and Brakenhoff RH: The molecular landscape of head and neck cancer. Nat Rev Cancer 18: 269-282, 2018.

4. Leemans CR, Braakhuis BJ and Brakenhoff RH: The molecular biology of head and neck cancer. Nat Rev Cancer 11: 9-22, 2011.

5. Oliva M, Spreafico A, Taberna M, Alemany L, Coburn B, Mesia R and Siu LL: Immune biomarkers of response to immune-checkpoint inhibitors in head and neck squamous cell carcinoma. Ann Oncol 30: 57-67, 2019.

6. Hira-Miyazawa M, Nakamura H, Hirai M, Kobayashi Y, Kitahara H, Bou-Gharios G and Kawashiri S: Regulation of programmed-death ligand in the human head and neck squamous cell carcinoma microenvironment is mediated through matrix metalloproteinase-mediated proteolytic cleavage. Int J Oncol 52: 379-388, 2018.

7. Zhou C, Ye M, Ni S, Li Q, Ye D, Li J, Shen Z and Deng H: DNA methylation biomarkers for head and neck squamous cell carcinoma. Epigenetics 13: 398-409, 2018.

8. Allameh A, Moazeni-Roodi A, Harirchi I, Ravanshad M Motiee-Langroudi M, Garajei A, Hamidavi A and Mesbah-Namin SA: Promoter DNA methylation and mRNA expression level of p16 gene in oral squamous cell carcinoma: Correlation with Clinicopathological Characteristics. Pathol Oncol Res 25: 1535-1543, 2019. 
9. Fomenkov A, Zangen R, Huang YP, Osada M, Guo Z, Fomenkov T, Trink B, Sidransky D and Ratovitski EA: RACK1 and stratifin target DeltaNp63alpha for a proteasome degradation in head and neck squamous cell carcinoma cells upon DNA damage. Cell Cycle 3: 1285-1295, 2004.

10. Mirza AH, Thomas G, Ottensmeier $\mathrm{CH}$ and King EV: Importance of the immune system in head and neck cancer. Head Neck 41: 2789-2800, 2019.

11. Rossa C Jr and D'silva NJ: Immune-relevant aspects of murine models of head and neck cancer. Oncogene 38: 3973-3988, 2019.

12. Pardoll DM: The blockade of immune checkpoints in cancer immunotherapy. Nat Rev Cancer 12: 252-264, 2012.

13. Bardhan K, Anagnostou T and Boussiotis VA: The PD1: PD-L1/2 pathway from discovery to clinical implementation. Front Immunol 7: 550, 2016

14. Wollenberg B: PD-1 antibodies in head-and-neck cancer. Lancet 393: 108-109, 2019.

15. Kansy BA, Concha-Benavente F, Srivastava RM, Jie HB, Shayan G, Lei Y, Moskovitz J, Moy J, Li J, Brandau S, et al: PD-1 Status in CD8+T cells associates with survival and Anti-PD-1 therapeutic outcomes in head and neck cancer. Cancer Res 77 6353-6364, 2017.

16. Bauml J, Seiwert TY, Pfister DG, Worden F, Liu SV, Gilbert J, Saba NF, Weiss J, Wirth L, Sukari A, et al: Pembrolizumab for platinum- and cetuximab-refractory head and neck cancer: Results from a single-arm, phase ii study. J Clin Oncol 35: 1542-1549, 2017

17. Pai SI, Zandberg DP and Strome SE: The role of antagonists of the PD-1: PD-L1/PD-L2 axis in head and neck cancer treatment. Oral Oncol 61: 152-158, 2016.

18. De Felice F, Tombolini M, Abate G, Salerno F, Bulzonetti N, Tombolini V and Musio D: Prognostic significance of the neutrophil/lymphocyte ratio in patients with non-human papilloma virus-related oropharyngeal cancer: A retrospective cohort study. Oncology 96: 8-13, 2019.

19. Huang SH, Waldron JN, Milosevic M, Shen X, Ringash J, Su J, Tong L, Perez-Ordonez B, Weinreb I, Bayley AJ, et al: Prognostic value of pretreatment circulating neutrophils, monocytes, and lymphocytes in oropharyngeal cancer stratified by human papillomavirus status. Cancer 121: 545-555, 2015.

20. Chew EY, Hartman CM, Richardson PA, Zevallos JP, Sikora AG, Kramer JR and Chiao EY: Risk factors for oropharynx cancer in a cohort of HIV-infected veterans. Oral Oncol 68: 60-66, 2017.

21. Faraji F, Fung N, Zaidi M, Gourin CC, Eisele DW, Rooper LM and Fakhry C: Tumor-infiltrating lymphocyte quantification stratifies early-stage human papillomavirus oropharynx cancer prognosis. Laryngoscope 130: 930-938, 2020.

22. Patel T, Morrison LK, Rady P and Tyring S: Epidermodysplasia verruciformis and susceptibility to HPV. Dis Markers 29: 199-206, 2010.

23. Madeleine MM, Carter JJ, Johnson LG, Wipf GC, Davis C, Berg D, Nelson K, Daling JR, Schwartz SM and Galloway DA: Risk of squamous cell skin cancer after organ transplant associated with antibodies to cutaneous papillomaviruses, polyomaviruses, and TMC6/8 (EVER1/2) variants. Cancer Med 3: 1440-1447, 2014.

24. Castro FA, Ivansson EL, Schmitt M, Juko-Pecirep I, Kjellberg L, Hildesheim A, Gyllensten UB and Pawlita M: Contribution of TMC6 and TMC8 (EVER1 and EVER2) variants to cervical cancer susceptibility. Int J Cancer 130: 349-355, 2012

25. Lazarczyk M, Dalard C, Hayder M, Dupre L, Pignolet B, Majewski S, Vuillier F, Favre M and Liblau RS: EVER proteins, key elements of the natural anti-human papillomavirus barrier, are regulated upon T-cell activation. PLoS One 7: e39995, 2012.

26. Crequer A, Picard C, Pedergnana V, Lim A, Zhang SY, Abel L, Majewski S, Casanova JL, Jablonska S, Orth G and Jouanguy E: EVER2 deficiency is associated with mild T-cell abnormalities. J Clin Immunol 33: 14-21, 2013.

27. Colevas AD, Yom SS, Pfister DG, Spencer S, Adelstein D, Adkins D, Brizel DM, Burtness B, Busse PM, Caudell JJ, et al: NCCN Guidelines Insights: Head and neck cancers, version 1.2018. J Natl Compr Canc Netw 16: 479-490, 2018.

28. Livak KJ and Schmittgen TD: Analysis of relative gene expression data using real-time quantitative PCR and the 2(-Delta Delta C(T)) method. Methods 25: 402-408, 2001.

29. Li B and Dewey CN: RSEM: Accurate transcript quantification from RNA-Seq data with or without a reference genome. BMC Bioinformatics 12: 323, 2011.

30. R Core Team: R: A language and environment for statistical computing. R Foundation for Statistical Computing, Vienna, 2014
31. Yoshihara K, Shahmoradgoli M, Martinez E, Vegesna R, Kim H, Torres-Garcia W, Treviño V, Shen H, Laird PW, Levine DA, et al: Inferring tumour purity and stromal and immune cell admixture from expression data. Nat Commun 4: 2612, 2013.

32. Li T, Fan J, Wang B, Traugh N, Chen Q, Liu JS, Li B and Liu XS: TIMER: A web server for comprehensive analysis of tumor-infiltrating immune cells. Cancer Res 77: e108-e110, 2017.

33. Chen B, Khodadoust MS, Liu CL, Newman AM and Alizadeh AA: Profiling tumor infiltrating immune cells with CIBERSORT. Methods Mol Biol 1711: 243-259, 2018.

34. Aran D, Hu Z and Butte AJ: xCell: Digitally portraying the tissue cellular heterogeneity landscape. Genome Biol 18: 220, 2017.

35. Nagy A, Lanczky A, Menyhart O and Győrffy B: Validation of miRNA prognostic power in hepatocellular carcinoma using expression data of independent datasets. Sci Rep 8: 9227,2018

36. Liang C, Kelsey KT, Mcclean MD, Christensen BC, Marsit CJ, Karagas MR, Waterboer T, Pawlita M and Nelson HH: A coding variant in TMC8 (EVER2) is associated with high risk HPV infection and head and neck cancer risk. PLoS One 10: e0123716, 2015.

37. Antonsson A, Law MH, Neale RE, Coman WB, Pryor DI; Study of Digestive Health (SDH), Porceddu SV and Whiteman DC: Variants of EVER1 and EVER2 (TMC6 and TMC8) and human papillomavirus status in patients with mucosal squamous cell carcinoma of the head and neck. Cancer Causes Control 27: 809-815, 2016

38. Jablonska S and Majewski S: Epidermodysplasia verruciformis: immunological and clinical aspects. Curr Top Microbiol Immunol 186: 157-175, 1994.

39. Majewski S, Jablonska S and Orth G: Epidermodysplasia verruciformis. Immunological and nonimmunological surveillance mechanisms: role in tumor progression. Clin Dermatol 15: 321-334, 1997.

40. Patel A S, Karagas MR, Pawlita M, Waterboer T and Nelson $\mathrm{HH}$ Cutaneous human papillomavirus infection, the EVER2 gene and incidence of squamous cell carcinoma: A case-control study. Int J Cancer. 122: 2377-2379, 2008.

41. Antonsson A, Law MH, Neale RE, Coman WB, Pryor DI; Study of Digestive Health (SDH), Porceddu SV and Whiteman DC: Erratum to: Variants of EVER1 and EVER2 (TMC6 and TMC8) and human papillomavirus status in patients with mucosal squamous cell carcinoma of the head and neck. Cancer Causes Control 27: 951, 2016

42. Henderson NC, Rieder F and Wynn TA: Fibrosis: From mechanisms to medicines. Nature 587: 555-66, 2020.

43. Su AI, Wiltshire T, Batalov S, Lapp H, Ching KA, Block D, Zhang J, Soden R, Hayakawa M, Kreiman G, et al: A gene atlas of the mouse and human protein-encoding transcriptomes. Proc Natl Acad Sci USA 101: 6062-6067, 2004.

44. Morgan AE, Davies TJ and Mc Auley MT: The role of DNA methylation in ageing and cancer. Proc Nutr Soc 77: 412-422, 2018.

45. Chatterjee $\mathrm{S}$ and Ahituv $\mathrm{N}$ : Gene regulatory elements, major drivers of human disease. Annu Rev Genomics Hum Genet 18 45-63, 2017

46. Pu M, Chen J, Tao Z, Miao L, Qi X, Wang Y and Ren J: Regulatory network of miRNA on its target: Coordination between transcriptional and post-transcriptional regulation of gene expression. Cell Mol Life Sci 76: 441-451, 2019.

47. Amaya-Uribe L, Rojas M, Azizi G, Anaya JM and Gershwin ME: Primary immunodeficiency and autoimmunity: A comprehensive review. J Autoimmun 99: 52-72, 2019.

48. Iwasaki A and Medzhitov R: Control of adaptive immunity by the innate immune system. Nat Immunol 16: 343-353, 2015.

49. Hammerbacher J and Snyder A: Informatics for cancer immunotherapy. Ann Oncol 28 (Suppl-12): xii56-xii73, 2017.

50. Kumar BV, Connors TJ and Farber DL: Human T cell development, localization, and function throughout life. Immunity 48 : 202-213, 2018

51. Park H, Li Z, Yang XO, Chang SH, Nurieva R, Wang YH, Wang Y, Hood L, Zhu Z, Tian Q and Dong C: A distinct lineage of CD4 T cells regulates tissue inflammation by producing interleukin 17. Nat Immunol 6: 1133-1141, 2005.

52. Scott M, Nakagawa M and Moscicki A: B. Cell-mediated immune response to human papillomavirus infection. Clin Diagn Lab Immunol 8: 209-20, 2001.

53. Jogdand GM, Mohanty S and Devadas S: Regulators of Tfh cell differentiation. Front Immunol 7: 520, 2016 
54. Renand A, Milpied P, Rossignol J, Bruneau J, Lemonnier F, Dussiot M, Coulon S and Hermine O: Neuropilin-1 expression characterizes $\mathrm{T}$ follicular helper ( $\mathrm{Tfh}$ ) cells activated during $\mathrm{B}$ cell differentiation in human secondary lymphoid organs. PLoS One 8: e85589, 2013.

55. Huang Y, Moreau A, Dupuis J, Streubel B, Petit B, Le Gouill S, Martin-Garcia N, Copie-Bergman C, Gaillard F, Qubaja M, et al: Peripheral T-cell lymphomas with a follicular growth pattern are derived from follicular helper T cells (TFH) and may show overlapping features with angioimmunoblastic T-cell lymphomas. Am J Surg Pathol 33: 682-690, 2009.

56. Schmitt N, Bentebibel SE and Ueno H: Phenotype and functions of memory Tfh cells in human blood. Trends Immunol 35 436-442, 2014

57. Yasuda K, Takeuchi Y and Hirota K: The pathogenicity of Th17 cells in autoimmune diseases. Semin Immunopathol 41: 283-297, 2019.

58. Chang SH: T helper 17 (Th17) cells and interleukin-17 (IL-17) in cancer. Arch Pharm Res 42: 549-559, 2019.

59. Goswami KK, Ghosh T, Ghosh S, Sarkar M, Bose A and Baral R: Tumor promoting role of anti-tumor macrophages in tumor microenvironment. Cell Immunol 316: 1-10, 2017.

60. Murray PJ: Macrophage Polarization. Annu Rev Physiol 79: 541-66, 2017.

61. Lefebvre JL, Sanes JR and Kay JN: Development of dendritic form and function. Annu Rev Cell Dev Biol 31: 741-777, 2015.
62. Cooper LA, Demicco EG, Saltz JH, Powell RT, Rao A and Lazar AJ: PanCancer insights from the cancer genome atlas: The pathologist's perspective. J Pathol244: 512-524, 2018.

63. Dunne EF and Park IU: HPV and HPV-associated diseases. Infect Dis Clin North Am 27: 765-78, 2013.

64. Goodman A: HPV testing as a screen for cervical cancer. BMJ 350: h2372, 2015.

65. Wang SS, Gonzalez P, Yu K, Porras C, Li Q, Safaeian M, Rodriguez AC, Sherman ME, Bratti C, Schiffman M, et al: Common genetic variants and risk for HPV persistence and progression to cervical cancer. PLoS One 5: e8667, 2010.

66. Yamada Y, Arai T, Kojima S, Sugawara S, Kato M, Okato A, Yamazaki K, Naya Y, Ichikawa T and Seki N: Regulation of antitumor miR-144-5p targets oncogenes: Direct regulation of syndecan-3 and its clinical significance. Cancer Sci 109: 2919-2936, 2018.

67. Lu P, Ding Q, Ding S, Fan Y, Li X, Tian D and Liu M: Transmembrane channel-like protein 8 as a potential biomarker for poor prognosis of hepatocellular carcinoma. Mol Clin Oncol 7: 244-248, 2017.

() $\Theta$ This work is licensed under a Creative Common Attribution-NonCommercial-NoDerivatives 4.0 International (CC BY-NC-ND 4.0) License. 